\title{
Balancing Accuracy and Meaning in Common-Pool Resource Theory
}

\author{
$\underline{\text { Michael Cox }}^{1,2}$
}

\begin{abstract}
Common-pool resources are managed in complex environments that are amenable to understanding, analysis, and management at multiple levels. This paper develops a heuristic criterion to identify the costs and benefits of adopting various levels of analysis when constructing theory for commonpool resource management. It argues that there is no single optimal level for such analysis. Instead, a tradeoff is posed where theories at higher levels tend to be more accurate but less meaningful than theories at lower levels.
\end{abstract}

Key Words: common-pool resources; complexity; institutional analysis; scale

\section{INTRODUCTION}

The motivation for this paper is a question posed by Holling et al. (2002: 63): "What is the appropriate scale of observation in our search for theories and actions for sustainable futures?" I adopt here the terminology as presented by Gibson et al. (2000: 218), who define scale as the "spatial, temporal, quantitative, or analytical dimensions used to measure and study any phenomenon." Scale is a type of dimension such as time or space, and level is a location along a scale, or "the units of analysis that are located at the same position on a scale" (p. 218 ), such as days or square meters. Cash et al. (2006) adopt this terminology and elaborate: "CCross-level' interactions refer to interactions among levels within a scale, whereas 'cross-scale' means interactions across different scales, for example, between spatial domains and jurisdictions." I infer the question Holling et al. are asking in this context to be: What is the appropriate "level" of observation within any particular scale? What units of analysis along various scales are useful in developing theories that relate social and ecological conditions to sustainable outcomes?

This paper addresses the question posed by Holling et al. (2002) in the context of the management of common-pool resources (CPRs), such as forests and fisheries, which are commonly recognized for the difficulties they present to users, political officials, and scholars. For users and officials, the difficulties lie in the collective-action problems that CPRs pose because of their high cost of exclusion and subtractability of use, meaning that it is difficult to exclude potential users from consuming the resource, and that one person's consumption subtracts from the amount available to others. A collective-action problem is a dilemma for a user community caused by a divergence between individual and community-level interests. In these situations, the pursuit of individual gain is collectively harmful, and it can be difficult to organize people to act collectively in pursuit of common interests.

The properties of CPRs lead to at least two types of collective-action problems in CPR management: those of resource appropriation and provision (Ostrom et al. 1994). An appropriation problem can result in overconsumption of a subtractable resource where an individual benefits from personal consumption at the expense of the community and the condition of the resource. A provision problem can result in underprovision of the infrastructure needed to appropriate a resource, such as an irrigation headworks. This occurs because it is difficult to exclude non-contributors from benefiting from, or freeriding on, the efforts of contributors. In order to effectively manage a CPR, incentives need to be provided to users to limit their consumption levels and boost their provision levels. As a result of these problems, the management of CPRs is not a simple task, and there is substantial 
documentation of both successes and failures of various CPR management regimes (National Research Council (NRC) 1986, NRC et al. 2002).

For scholars studying the ways CPRs are managed, the problem is theoretical and results from the enormous number of social and ecological variables involved in CPR settings that affect outcomes and each other in complex ways, making theoretic generalization difficult (Agrawal 2002). A common simplifying device employed by resource users and scholars alike to deal with this complexity is to group social or ecological phenomena on a particular level into aggregate concepts on a higher level based on perceived functional similarities between them. This is aggregation along the analytical dimension from Gibson et al. (2000). Analytical levels exist in a hierarchy of related concepts and "are on a conceptual scale based on functional relationships rather than on a spatial or temporal scale" (Gibson et al. 200: 221). The concept of a CPR itself depends on this process, where a large variety of social-ecological phenomena are perceived to share important functional characteristics and thus to belong to a common set of objects that can be conceived of, analyzed, and managed in similar ways.

When confronting the enormous complexity of CPR settings, appealing to higher levels for the sake of analytical tractability seems like an inevitable step for users, political officials, and scholars to take. An unresolved question for scholars is how high a level should they appeal to when constructing theories about CPR management? This paper will help answer this question by exploring a trade-off between accuracy and meaningfulness that occurs when the level of CPR theory increases or decreases. The basic hypothesis to be explored is that at coarser or higher levels, theories become successively more accurate in their predictions but less meaningful. Thus, as analysts, we are constrained by a trade-off between high-level theories that are more accurate but less meaningful and low-level theories that are less accurate but more meaningful.

\section{LEVIN'S PRINCIPLE}

Addressing the question posed by Holling et al. (2002) is complicated by the fact that a single optimal level of analysis and theory construction for effective CPR management does not exist. Nor is there an optimal level for science generally. This is because systems in our world are hierarchical and nearly decomposable, with patterns and functions that emerge at one level caused by interactions between patterns and functions at other levels. Different levels are interdependent. Additionally, patterns at one level cannot be reduced to patterns at another level. Thus, no single privileged level of a system exists to which we can reduce the processes and patterns from all other levels to fully understand the system. A hierarchical system is composed of levels, and a nearly decomposable system is one where each level is composed of systems, which are themselves composed of subsystems on a lower level, with relatively weak interactions between subsystems relative to the interactions taking place within subsystems. Herbert Simon (1995: 26) describes several examples of this characteristic:

A familiar example is the molecule, composed of atoms, which are composed of electrons and nuclei, which are composed of elementary particles, which are composed of quarks. Another example is the biological organism, which is composed of organs, which are composed of cells, which contain organelles, which are composed of molecules, and so on. A third example is human society, which is composed of economic, social, and religious organizations, these, in turn, of subgroups, down to the level of families. A social example is more complex than the others, since each individual may belong to a number of the larger subgroups-a family, a business firm, a church, and so on.

Gibson et al. (2000: 220) refer to such a nearly decomposable ordering where subunits interact to form units as a "constitutive hierarchy." Any theory describing the behavior of a complex, nearly decomposable system may relate objects across scales and across levels within those scales and will rely on the patterns and categories that emerge at those particular levels along those particular scales. At the same time, these patterns interact with and result from processes at higher and lower levels along their respective scales. To understand a system at one set of levels along one set of scales is not to understand the system entirely. Traditionally, scientific disciplines are divided up based on the level or range of levels on which they are focused (e.g., physics, chemistry, or biology). The research questions of how to best manage CPRs, however, involve complex, nearly decomposable systems that 
are not conducive to one optimal level of analysis along any particular scale. Given the necessity of focusing on a particular set of analytical units and the incomplete picture this reveals of a complex, nearly decomposable system with cross-scale and cross-level interactions, it is left up to scholars to determine the more or less useful levels.

In this context, Simon Levin (1999: 26)—using "scale" where I have used "level"-makes the important point that "variation is typically greater at smaller scales than it is at large scales." Low-level states in a multilevel system generally vary more than high-level states. Moreover, "For many phenomena of interest, a coarser scale allows one to average over variations and make more definitive statements, whether about space, time, or the ensemble of agents in a complex adaptive system" (Levin 1999: 64). A theory that describes high-level behavior will be more accurate because the phenomena it relates are less varied.

Levin applies the same thinking to spatial, temporal, ecological, and economic functional groups. Regardless of the type of scale, the principle remains the same: ignore the variations between the units being aggregated in order to treat them analytically as a single unit. This can mean lumping days into months, square meters into square kilometers, species into functional groups, and, as we shall see, detailed institutional rules in CPR settings into institutional design principles.

The principle is best illustrated with an example: at exceedingly low levels, the behavior of billions of individual particles is impossible to precisely predict or describe. To describe the state of the system would require knowing the position and velocity of each individual particle. We have developed, however, quite effective macro-level approximations of the behavior of liquids and gases (such as the ideal gas law, PV $=n R T$ ) despite our inability to predict where each particular molecule in a gas might go next. The essential mechanism for Levin's principle and in this example is that there exist a large number of microstates at one level that yield essentially the same emergent macrostate at a higher level. The microstates can change in a variety of ways without changing the macrostate, or at least changing it very little relative to micro-level changes. There are millions of possible arrangements of water molecules in a specified volume that yield the same temperature, for example.
Of course, some low-level information is lost at this higher level, but in many cases, this is more than compensated for by the gains in analytical tractability. We appeal to higher levels because we have incomplete models of the systems we analyze; we cannot predict with precision the development of one microstate to another due to a lack of theory or measurement tools. Fortunately, we do not have to in order to usefully analyze those systems because there is a one-to-many relationship between a macrostate and a set of microstates.

Levin demonstrates how increasing the level of analysis can increase predictive accuracy by decreasing variation when he describes a theory that relates certain plant types to climatic conditions, namely temperature and moisture. Given certain climatic conditions, we can expect certain flora to be present. We can choose to specify what we mean by flora at one of several levels along an analytical scale: we could choose, for example, the level of species or the level of a larger functional group that aggregates a set of species based on important similarities, such as therophytes or phanerophytes. A theory that uses a functional group will more often be confirmed than a theory that uses the species level, because there is less variation in the presence or absence of a functional group than in the presence or absence of a particular species within that functional group. As long as any one of the species of the functional group appears under given climatic conditions, the functional group is held to be present as well, confirming the theory.

\section{APPLICATION TO COMMON-POOL RESOURCE THEORY}

Within the CPR literature, relevant variables affecting outcomes have often been grouped into one of three categories: community attributes, biophysical properties, and institutions. Institutions are defined by Ostrom (1986: 5; emphasis in original) as "potentially linguistic entities . . . that refer to prescriptions commonly known and used by a set of participants to order repetitive, interdependent relationships" where "prescriptions refer to which actions (or states of the world) are required, prohibited, or permitted." Institutions represent the rules used within a community as it attempts to coordinate mutually beneficial behavior and resolve collective-action problems. They are uniquely important from a policy analysis point of view because they are most directly endogenous to 
decisions made by resource users, managers, and policymakers.

Institutional analysts interested in natural resource management can take advantage of Levin's principle in ways similar to those just described. Instead of aggregating only physically tangible phenomena, however, they have the additional and more abstract task of analyzing institutions, which are infamously intangible and difficult to measure. Still, the principle of aggregating distinct but similar phenomena for the sake of analytical tractability remains viable.

An example of an institutional analysis that implicitly uses Levin's theorem is Ostrom's (1990) design principles for robust community-based CPR management. Ostrom had initially given herself the task of identifying common rules in use across a variety of long-lasting CPR user communities. Facing the overwhelming diversity of rules being used by communities managing CPRs, Ostrom had to resort to a higher analytical level than the rules themselves in order to make viable predictions across a range of cases. She chose to develop "design principles" characterizing sets of rules as opposed to particular rules. Each design principle states general institutional conditions that make it more likely that a community will sustainably manage a CPR.

We can think of individual rules as microstates and a design principle as a macrostate whose presence is confirmed by a variety of particular rules as long as they satisfy the conditions the principle specifies. Ostrom observed too much variation in the microstates (specific rules used by communities managing CPRs) for her to produce an accurate theory at that level. She states (1990: 89-90):

The specific operational rules in these cases differ markedly from one another. Thus, they cannot be the basis for an explanation across settings. ... Instead of turning to the specific rules, I turn to a set of design principles that characterize all of these robust CPR institutions . . . by 'design principle' I mean an essential element or condition that helps to account for the success of these institutions in sustaining the CPRs and gaining the compliance of generation after generation of appropriators to the rules in use.
The relationship between a particular rule and a design principle is analogous to the relationship between a species and a functional group used in Levin's example. Because there are many rules that can satisfy a design principle, there will be less variation in the presence or absence of a design principle in a user community than in the presence or absence of a particular rule. Because of this decrease in variation, theories that predict sustainable outcomes based on a design principle will be confirmed much more by observations than those that predict sustainable outcomes based on a precise formulation of a particular rule.

For example, the second design principle stipulates that sustainable outcomes are more likely to result when "appropriation rules restricting time, place, technology, and/or quantity of resource units are related to local conditions and to provision rules requiring labor, material, and/or money" (Ostrom 1990: 90). A large set of specific rules could satisfy this condition. Whenever one of these institutional arrangements is found in a robust CPR management regime, the principle is confirmed and the theory's accuracy improved. By increasing the level of her analysis, Ostrom improved the accuracy and applicability of the theoretic arguments she could make. She did just what Levin suggested: suppress detail of variations between units (rules) at one level by aggregating them into a higher-level unit (design principle) based on important common features.

\section{THE TRADE-OFF}

The question to be posed-once we understand the possibilities of Levin's hypothesis-is "How far up should we go, or, what are the possible disadvantages of increasing the level of our units of analysis?" Why did Ostrom stop at the level of a design principle, and what is the cost of increasing the level from a theory that uses a rule to one that uses a design principle? Gell-Mann (1995: 20) recognized the trade-off involved here in his discussion of complex adaptive systems and their perception of their environment. He states that complex adaptive systems (which include humans) face "tradeoffs between coarseness for manageability of information and fineness for adequate picture of the environment." Levin (1992: 1947), again using scale where I am using level, reflects on the tradeoff: "This is the principal technique of scientific inquiry: by changing the scale of description, we move from unpredictable, unrepeatable individual 
cases to collections of cases whose behavior is regular enough to allow generalizations to be made. In so doing, we trade off the loss of detail or heterogeneity within a group for the gain of predictability." Boulding (1956: 197-198), in formulating his recommendations for the paradigm of general systems theory, describes this trade-off as well.

This paper places this trade-off in terms of accuracy vs. meaningfulness: as we increase the level of the units of analysis in our theory, we may improve our ability to make accurate predictions across a diversity of cases; at the same time, we render them less meaningful. By accuracy I mean the percentage of cases or observations that prove the theory to be correct. Our tolerance for theories with less than $100 \%$ accuracy results from our incomplete knowledge of the systems those theories describe and the mechanisms that drive them. If we interpret the theory as being more incomplete than incorrect, we keep it.

Meaningfulness is a trickier concept to unpack. Here, again, Levin (1999) is helpful. He cautions against excessively high levels of aggregation if they conceal important variations between the units being aggregated, and places this concern in the context of a loss of meaning. One example he uses is the average temperature on the earth's surface. This is, for many purposes, not a very meaningful concept because of the tremendous differences in temperature between regions on the globe. It does not help me personally very much to read a morning weather report that contains not the local temperature but the global average.

This point reveals that meaning is always relative to a particular perspective. I do not live on the entire world, I live in a particular spot on it. The more my spot differs from the others whose temperatures contributed to the calculation of the mean global temperature, the less meaningful and useful is that concept for me. At the same time, a theory that relates increases in atmospheric $\mathrm{CO}_{2}$ levels to increases in mean global temperature will be much more accurate than a theory that attempts to relate them to temperature increases in a small section of the globe because the global average varies less than a local average. This is the balance, or trade-off.

Another example of this trade-off is the average yearly rainfall for an area, which is less meaningful if the distribution of rainfall within that year is highly uneven. This is the reason why we often use modes and medians instead of means to represent numerical data with large standard deviations because in these cases the mean is not particularly meaningful or representative. The basic lesson is that concepts based on the aggregation of highly varied units are less meaningful and produce less meaningful theory when used. More important information describing low-level diversity is lost. This is the risk that Ostrom (1990) took when she constructed her design principles: the risk that they might lose meaning and be less applicable to particular CPR settings where someone might attempt to apply them. It is unsurprising then that some have criticized her approach as not being nuanced enough to capture case-specific or lowlevel complexity and variability (Cleaver 2000, Young 2002b).

Both meaningfulness and accuracy are theoretically useful. Accuracy is useful because it means that the theory will be confirmed more frequently over time or across spatial distances. An accurate theory explains a lot with a little, and indeed many of history's most famous theories are valued because they dojust that. Parsimony has long been a standard value in the philosophy of science beginning with the heuristic of Occam's razor. Meaningfulness is important because the application of a theory always occurs at a particular time and place. The less meaningful a theory is, the more variation there is in the units aggregated in its concepts, and the less representative it will be of a particular situation.

\section{POLICY ANALYSIS AND MEANING}

Although Ostrom could be criticized for adopting a higher analytical level than a particular rule, it turns out that her analysis was at a much lower level than is common in many natural resource policy analyses. The high levels used in mainstream policy analysis are most commonly a result of the statemarket dichotomy as presented in popular policy analysis textbooks (Weimer and Vining 2005). One of the most revered theories in policy analysis is that markets distribute private goods efficiently. This theory has noticeably permeated into policy-making circles where, for example, moves toward privatization of service provision are justified by claims of market efficiency.

This posits a theoretical relationship between three concepts: (1) markets, (2) private goods, and (3) 
efficient outcomes. Yet, all three are quite coarse, including extremely heterogeneous phenomena. The water markets mediated by the state government in New Mexico bear little resemblance to the informal barter markets extant within Hispanic irrigation communities in that state, let alone to something like a foreign stock exchange. And yet, the above proposition demands we treat them as quite similar in fundamental respects. Equally, there is an enormous variety in what we could label as private goods, and efficiency is open to essentially an infinite variety of formulations.

Thus, a theory stating that markets yield efficiency is not meaningful as policy advice from the perspective of someone trying to determine how to distribute a particular good. Unanswered questions include what "kind" of market, with what particular rules and regulations and monitoring, should be implemented? What exactly is the good? Does it have lower-level properties that distinguish it from other private goods? A theory operating at the level of markets and private goods is not helpful in answering these practical questions.

Although markets are held to be optimal for private goods, traditional theory also predicts that states are the best source of provision and management for more public goods, including CPRs. There are several problems with this presumption. First, states as a policy instrument category are just as meaningless as markets because of the diversity of phenomena that they represent. Actual states differ significantly in important ways, including their level of accountability to their populations and their economic resources. A major problem in many developing countries, following the nationalization of natural resource management, has been resource degradation because the states do not have the money or officials to actually manage their resources after claiming legal responsibility for them. In developing countries, this nationalization has often led to an open-access property rights arrangement and severe resource degradation.

Additionally, can it be that privatization and nationalization are our only institutional alternatives? The answer is surely no. Let us hope, for the sake of institutional adaptability, that we have more institutional options available to us than is suggested by the state-market framework. Ostrom (2005: 256) elaborates:

Continuing to presume that complex policy problems are simple problems that can be solved through the adoption of simple designs that are given general names, such as private property, government ownership, or community organization, is a dangerous academic approach. Dichotomizing the institutional world into 'the market' as contrasted to 'the state' is so grossly inadequate and barren that it is surprising how the dichotomy survives as a basic way of organizing academic studies and policy advice. Oversimplification of our design options is dangerous since it hides more of the working parts needed to design effective, sustainable institutions than it reveals.

The point here is that the organizing concepts of states and markets are much too aggregated to serve as meaningful analytical tools in CPR settings unless they are extensively complemented by an overarching framework that places them in a more useful context.

\section{MOVING FORWARD WITH A COMPLEX FRAMEWORK}

Moving forward with CPR theory in the context of the trade-off described requires a framework that explicitly recognizes the complex, hierarchical, and nearly decomposable nature of the systems that produce CPRs as emergent phenomena. Meanwhile, institutional analysts studying such complex systems need to recognize the limitations on the precision of the predictions that they can make. Graham Marshall (2003: 8) makes the case that in these circumstances analysts should conduct themselves the way active participants in those systems do, that is, behave inductively.

An inductive approach to identifying institutional design principles involves searching for regularities in the behavior and performance of particular institutional forms across multiple case studies. A metatheoretical framework can help to store, organize and interrogate the data from the case studies systematically, in order to facilitate recognition of robust patterns in the data that might serve as design principles.

Ostrom (2007) has constructed such a metatheoretical framework that explicitly reflects important properties of complex systems, most importantly their hierarchical nature. Ostrom 
divides the framework's conceptual levels into tiers, with tier 1 being the highest, and lower tiers containing subtypes of the variables listed in tier 1 . The framework begins by identifying several basic variable types that affect interactions and outcomes in situations where CPRs are managed: (1) the resource system, (2) the resource units produced by this system, (3) the properties of the user community, (4) the institutions/governance system, (5) the socioeconomic and political setting, and (6) related ecosystems (Ostrom 2007: 15182). Each of these variables is highly aggregated relative to lower-level variables, and thus will yield comparatively more accurate and less meaningful theories when used. The utility of Ostrom's framework is that it is multilevel and is populated not just by these variables but also by subtypes, and subtypes of subtypes.

Using this framework thus allows analysts of CPR management regimes to decide at which level they wish to conduct their analysis for each main variable type from tier 1. In discussing this multilevel property, Ostrom says "How far down or up a conceptual hierarchy a researcher needs to proceed depends on the specific empirical or policy question under investigation" (Ostrom 2007: 15182). Ostrom recommends defaulting at the top tier, and then proceeding downwards as additional detail is required by a particular case or research question. This is a reasonable approach for the construction of theory as well.

In the language used earlier, variation in microstates is what initially drives aggregation in order to produce reasonably accurate theory. If this variation becomes too extensive along the metric by which units are aggregated or extensive along alternative metrics, the macrostate will not be representative of them. Starting at the highest tier and concomitant level of accuracy, this framework then allows for an analyst to increase the meaningfulness of their theory by lowering the level of a particular variable as needed by extensive lower-level variations.

\section{CROSS-LEVEL THEORY}

This point concerning relationships between microstates and macrostates at different analytical levels highlights the need to develop cross-level theories of institutional arrangements. When we try to determine how heterogeneous are the units used to construct a higher-level aggregate as described above, we cross levels along an analytical scale through what Gibson et al. (2000) define as a constitutive hierarchy. In such a hierarchy, one "level can combine into new units that have new organizations, functions, and emergent properties" (Gibson et al. 2000: 220-221). The question is: What types of rules through their interactions at one level can be said to yield a particular institutional arrangement such as a market at a higher analytical level? The issue here is as much definitional as it is causal. We need theories that specify these relationships so that we can better understand how markets actually work and how meaningful they can be as analytical tools. Additionally, we need to be able to meaningfully distinguish between when a market is present and when one is not, so that we may relate its presence or absence to observed outcomes.

The analytical scale is not the only important dimension when we are focusing on cross-level institutional links. Oran Young (2002a), for example, considers how the institutional interplay between institutional arrangements at distinct levels of social organization affects human-environment interactions. Cash et al. (2006) describe this as cross-level interactions along a jurisdictional scale. A central point that Young (2002a: 266) makes is strikingly similar to the one embodied in Ostrom's (2007) tiered framework:

I argue that it seldom makes sense to focus exclusively on finding the right level or scale at which to address specific problems arising from human/environment relations. Although small-scale or local arrangements have well-known problems of their own, there are good reasons to be wary of the pitfalls associated with the view that the formation of regimes at higher levels of social organization offers a straightforward means of regulating human activities involving large marine and terrestrial ecosystems. In most cases, the key to success lies in allocating specific tasks to the appropriate level of social organization and then taking steps to ensure that cross-scale interactions produce complementary rather than conflicting actions.

One level will not do for either theory construction or management. Moreover, the analytical concern with low-level heterogeneity can be usefully carried over to management. The more heterogeneous are 
lower-level jurisdictions, the more apprehensive we ought to be about applying one homogeneous set of rules to all of them. Instead of sacrificing analytical meaning, however, now we risk sacrificing sustainable outcomes for real communities. Theory and management are not entirely independent of course: meaningless theories encourage excessively homogeneous policy.

Understanding cross-level institutional links is important for CPR management because societies and ecosystems are complex systems with crosslevel behaviors along several scales. Limited crosslevel institutional nesting to mirror the ecological reality hampers our ability to perceive and respond to these behaviors. Additionally, a part of this complexity involves the incidence of collectiveaction problems at multiple levels of biological and social organization. Simply because a community has managed to successfully resolve its internal conflicts of interest does not mean that there will be no intercommunity social dilemmas when that community is one of many managing a larger CPR such as a watershed or a forest. We need cross-level theory that helps us understand how the resolution of collective-action problems at one level affects the incidence and severity of collective-action problems at higher levels, or more generally the cross-level jurisdictional interplay between institutions. Indeed, the very notion of a collective-action problem depends on an understanding of the crosslevel interactions between individual and collective-level interests.

Ostrom (1990) begins a treatment of cross-level jurisdictional interactions in design principles seven and eight, which state respectively that "the rights of appropriators to devise their own institutions are not challenged by external government authorities" and that in complex social-ecological systems, "appropriation, provision, monitoring, enforcement, conflict resolution, and governance activities are organized in multiple layers of nested enterprises" (Ostrom 1990: 90). Agrawal (2002) argues that several major works in the literature on CPR management, including Ostrom (1990), have focused too much on local low-level institutional processes to the exclusion of "the external social, institutional, and biophysical environment" (Agrawal 2002: 56). Since these major works, however, interest in understanding cross-level institutional and social-ecological links has grown (Berkes 2002, Young 2002a, Folke et al. 2007).

\section{CONCLUSION}

Traditionally, the level of analysis is what distinguishes a particular branch of science from others (e.g., physics, chemistry, and biology), and so within the research program of each branch, questions regarding the most appropriate levels of analysis can often be more easily elided. The approach to science implied by nearly decomposable complex systems, however, must consider what may be more or less appropriate levels of analysis for particular questions, and cannot presume that one level is ideal for all purposes.

Moreover, a science that allows for the coexistence of theories describing the same phenomenon at multiple levels requires that we abandon what Marshall (2005: 10) calls the principle of monism, or "that there is a single best way of understanding any given natural system." The usefulness of a theory via its meaningful content and accuracy is relative to a particular perspective: it is useful for some particular person or group.

If individuals are making decisions at the jurisdictional level of an irrigation system, for example, they have to take the details of that particular level into account. From the perspective of a national policy maker, theory needs to be somewhat more general to maintain some degree of accuracy across the settings that are of interest, but still at a much lower analytical level, I would argue, than that where all types of institutional arrangements are grouped as being either states or markets. Comanagement between actors across jurisdictional levels is an increasingly recognized approach to natural resource governance (Olsson et al. 2004), but if user groups and policy makers are to implement this approach effectively, they each need their own theoretical statements and the means of communicating these statements to each other within some common framework such as the one presented by Ostrom (2007) above.

Finally, the effective management of CPRs requires a science that recognizes the important cross-level and cross-scale interactions that complex systems exhibit (Levin 1992). Moreover, we need criteria and heuristics to guide our navigation between these different levels once they are made explicit to us. We need to be aware of the costs and benefits of adopting one level for analysis and theory development over others. This paper is an attempt to contribute to that awareness. 
Responses to this article can be read online at:

http://www.ecologyandsociety.org/voll3/iss2/art44/responses/

\section{Acknowledgments:}

I am grateful to Marco Janssen and Elinor Ostrom for reading previous drafts, as well as to my fellow panel members and attendees at the Midwest Political Science Conference 2008 National Conference, where I delivered a previous version of this paper and received helpful comments. I want to thank Patty Lezotte for editing the final draft. Finally, the author acknowledges financial support for this work under National Science Foundation grant BCS-0527744, as well as from the Workshop in Political Theory and Policy Analysis at Indiana University.

\section{LITERATURE CITED}

Agrawal, A. 2002. Common resources and institutional sustainability. Pages 41-85 in National Research Council, Committee on the Human Dimensions of Global Change, E. Ostrom, T. Dietz, N. Dolšak, P. C. Stern, S. Stonich, and E. Weber, editors. The drama of the commons. National Academy Press, Washington, D.C., USA.

Berkes, F. 2002. Cross-scale institutional linkages: perspectives from the bottom up. Pages 293-321 in National Research Council, Committee on the Human Dimensions of Global Change, E. Ostrom, T. Dietz, N. Dolšak, P. C. Stern, S. Stonich, and E. Weber, editors. The drama of the commons. National Academy Press, Washington, D.C., USA.

Boulding, K. E. 1956. General systems theory: the skeleton of science. Management Science 2(3):197208.

Cash, D. W., W. Adger, F. Berkes, P. Garden, L. Lebel, P. Olsson, L. Pritchard, and O. Young. 2006. Scale and cross-scale dynamics: governance and information in a multilevel world. Ecology and Society 11(2): 8. [online] URL: http://www.ecology andsociety.org/vol11/iss2/art8/.

Cleaver, F. 2000. Moral ecological rationality, institutions and the management of common property resources. Development and Change 31:361-383.

Folke, C., L. Pritchard, F. Berkes, J. Colding, and U. Svedin. 2007. The problem of fit between ecosystems and institutions: ten years later. Ecology and Society 12(1): 30. [online] URL: http://www.e cologyandsociety.org/vol12/iss1/art30/.

Gell-Mann, M. 1995. Complex adaptive systems. Pages 11-23 in H. J. Morowitz and J. L. Singer, editors. The mind, the brain, and complex adaptive systems. Addison Wesley Longman, Reading, Massachusetts, USA.

Gibson, C.C., E. Ostrom, and T. K. Ahn. 2000. The concept of scale and the human dimensions of global change: a survey. Ecological Economics 32:217-239.

Holling, C. S., L. H. Gunderson, and G. D. Peterson. 2002. Sustainability and panarchies. Pages 63-102 in L. H. Gunderson and C. S. Holling, editors. Panarchy: understanding transformations in human and natural systems. Island Press, Washington, D.C., USA.

Levin, S. A. 1992. The problem of pattern and scale in ecology: the Robert H. MacArthur award lecture. Ecology 73(6):1943-1967.

Levin, S. A. 1999. Fragile dominion: complexity and the commons. Perseus Books, Cambridge, Massachusetts, USA.

Marshall, G. 2003. Towards a resource economics for adaptive managers. Paper presented at the 47th Annual Conference of the Australian Agricultural and Resource Economics Society, 12-14 February 2003, Fremantle, Australia.

Marshall, G. 2005. Economics for collaborative environmental management: renegotiating the commons. Earthscan, Sterling, Virginia, USA.

National Research Council (NRC). 1986. Proceedings of the conference on common property resource management. National Academy Press, Washington, D.C., USA.

NRC, Committee on the Human Dimensions of Global Change. E. Ostrom, T. Dietz, N. Dolšak, P. Stern, S. Stonich, and E. Weber, editors. 2002. 
The drama of the commons. National Academy Press, Washington, D.C., USA.

Olsson, P., C. Folke, and F. Berkes. 2004. Adaptive comanagement for building resilience in socialecological systems. Environmental Management 34 (1):75-90.

Ostrom, E. 1986. An agenda for the study of institutions. Public Choice 48(1):3-25.

Ostrom, E. 1990. Governing the commons: the evolution of institutions for collective action. Cambridge University Press, New York, New York, USA.

Ostrom, E. 2005. Understanding institutional diversity. Princeton University Press, Princeton, New Jersey, USA.

Ostrom, E. 2007. A diagnostic approach for going beyond panaceas. Proceedings of the National Academy of Sciences 104(39):15181-15187.

Ostrom, E., R. Gardner, and J. M. Walker. 1994. Rules, games and common-pool resources. University of Michigan Press, Ann Arbor, Michigan, USA.

Simon, H. A. 1995. Near decomposability and complexity: how a mind resides in a brain. Pages 25-43 in H. J. Morowitz and J. L. Singer, editors. The mind, the brain, and complex adaptive systems. Addison Wesley Longman, Reading, Massachusetts, USA.

Weimer, D. L., and A. R. Vining. 2005. Policy analysis: concepts and practice. Fourth edition. Prentice Hall, Upper Saddle River, New Jersey, USA.

Young, O. 2002a. Institutional interplay: the environmental consequences of cross-scale interactions. Pages 263-291 in National Research Council, Committee on the Human Dimensions of Global Change, E. Ostrom, T. Dietz, N. Dolšak, P. C. Stern, S. Stonich, and E. Weber, editors. The drama of the commons. National Academy Press, Washington, D.C., USA.

Young, O. 2002b. The Institutional dimensions of environmental change: fit, interplay, and scale. MIT Press, Cambridge, Massachusetts, USA. 